\title{
Políticas de promoción a la agricultura familiar en la zona periurbana de Río Gallegos (2007 - 2017). Un análisis desde el punto de vista de los derechos humanos
}

\section{Policies on promotion of familiar agriculture in the metropolitan area of Rio Gallegos (2007 - 2017). An analysis from a point of view of human rights}

\author{
Carolina Musci $^{1}$, Claudia Mansilla ${ }^{1}$, Gina Lipka ${ }^{2}$, Yamile Cárcamo ${ }^{1}$ \\ emusci@uarg.unpa.edu.ar, cleo.mansilla@gmail.com,lipka.gina@inta.gob.ar, \\ yamile.carcamo@gmail.com \\ ${ }^{1}$ Instituto de Trabajo Economía y Territorio (ITET) Unidad Académica Río Gallegos \\ Universidad Nacional de la Patagonia Austral. Av. Piloto Rivero s/n. Río Gallegos, Santa \\ Cruz, Argentina. \\ ${ }^{2}$ Escuela de Trabajo Social. Unidad Académica Río Turbio. Universidad Nacional de la \\ Patagonia Austral.
}

Recibido: 11/07/2019. Aceptado: 28/10/2019

\section{RESUMEN}

El objetivo del trabajo es identificar y valorar la política pública vigente en la ciudad de Río Gallegos, en relación con la promoción de la agricultura familiar entre los años 2007 - 2017. La indagación identifica los programas y planes vigentes durante ese período, sus objetivos y las instituciones involucradas en esta actividad. Para ello se realizó un relevamiento de planes, programas y documentos institucionales, fichaje y sistematización de la información obtenida para su posterior análisis. Este análisis se orienta a determinar la pertinencia de la oferta de la política pública para alcanzar las metas definidas por el Objetivo de Desarrollo Sostenible 2: Hambre cero, de la Agenda de Desarrollo Sostenible 2030, y a calificarla en relación con algunos indicadores de Capacidad estatal propuestos por el Grupo de Trabajo para la medición del Protocolo de San Salvador. De esta manera se pretende generar conocimiento útil, respaldado en información empírica, que potencialmente ayude a mejorar la formulación de propuestas en las agendas de gobierno municipal y provincial, que sean cada vez más acordes con los estándares que definen los Pactos y Tratados internacionales para el cumplimiento efectivo de los derechos humanos.

Palabras clave: Agricultura familiar; Políticas Públicas; Río Gallegos; Derechos Humanos.

\begin{abstract}
The aim of this paper is to identify and value the actual public policy in Rio Gallegos city in relation with the promotion of familiar agriculture between 2007-2017. The inquiry identifies the relevant plans and programmes during the period, their objectives and the institutions involved in this activity.In order to do so, a survey of plans, programmes and institutional documents was carried out, and the information gathered was filed and sistematized for further analysis. The analysis was intended to decide over the relevance of the offering of public policies to achieve the aims of the second objective of Sustainable Development: Zero Hunger, present in the Sustainable Development Agenda 2030, and to qualify it in relation with quality indicators of State Capacity advanced by the Task Force for Measuring of the
\end{abstract}


San Salvador Convention. In this way we intend to produce useful knowledge, backed by empirical data, that will potentially help improve the formulation of proposals in local and state government agendas, increasing their compatibility with the standards defined by international Pacts and Treaties on the efective compliance of human Rights.

Key words: Familiar Agriculture; Public Policies; Rio Gallegos; Human Rights.

\section{INTRODUCCIÓN}

El presente informe es el resultado de un trabajo de investigación que realizamos un grupo de investigadoras de la UNPA en el marco de la primera convocatoria de Investigación sobre Políticas Públicas Sociales.

Desde fines de la década de 1990, se observa en la zona periurbana de la ciudad de Río Gallegos la presencia de unidades familiares dedicadas a la producción agrícola. Aunque al principio estas unidades familiares pudieron estar asociadas a una estrategia de supervivencia para asegurar el autoconsumo, poco a poco comenzaron a crecer y comercializar su excedente transformando estas zonas en espacios con características propias del entorno rural.

Las actividades agrícolas que se desarrollan en esta zona riogalleguense durante el período 2007 - 2017 son: la producción animal (conejos, aves, ovinos, equinos, porcinos, peces), la apicultura, la agroindustria (aceites, bebidas, jaleas, lácteos, panificados), la producción vegetal (hortalizas, frutales, forrajeras, especias, plantas medicinales, ornamentales) y también las artesanías y el agroturismo. Todas ellas están contempladas en el art. 5 de la Ley Nacional $\mathrm{N}^{\circ} 27.118$ de Reparación Histórica de la Agricultura Familiar (AF) -sancionada en 2014 pero hasta la actualidad, no reglamentada-. Esta Ley obliga al Estado nacional a intervenir, promoviendo e impulsando la AF a partir del reconocimiento del agricultor/a como sujeto social protagónico del espacio rural y por ende titular de derechos.

La atención de la AF está contemplada también en el Sistema Internacional de Derechos Humanos al incluir la cuestión de la seguridad alimentaria y postular el derecho básico a la alimentación. Específicamente el Pacto Internacional de Derechos Económicos, Sociales y Culturales (PIDESC), en el artículo 11 postula el compromiso de los Estados a "Mejorar los métodos de producción, conservación y distribución de alimentos mediante la plena utilización de los conocimientos técnicos y científicos, la divulgación de principios sobre nutrición y el perfeccionamiento o la reforma de los regímenes agrarios de modo que se logren la explotación y la utilización más eficaces de las riquezas naturales".

De la misma manera, el Protocolo de San Salvador (PSS), pilar fundamental del Sistema Interamericano de Derechos Humanos (SIDH), en su artículo 12 respecto del derecho a la alimentación, sostiene que a fin de lograr que toda persona acceda a una nutrición adecuada, que le asegure la posibilidad de gozar del más alto nivel de desarrollo físico, emocional e intelectual "los Estados Partes se comprometen a perfeccionar los métodos de producción, aprovisionamiento y distribución de alimentos".

Estos Pactos Internacionales, obligan a los Estados firmantes -entre ellos la Argentina- a garantizar el derecho a la alimentación. Además de esa obligación, los Estados asumen un compromiso de desarrollo según la Agenda de Desarrollo Sostenible 2030 acordada por los Estados Miembros de la ONU. Esta Agenda es un plan de acción mundial que pretende guiar las decisiones políticas estableciendo metas de desarrollo para 2030 en función de 17 objetivos (ODS). Las metas propuestas para el ODS 2: Hambre cero, incluyen el sostenimiento y la promoción de la AF en pos de la seguridad alimentaria, la sostenibilidad de la producción agrícola, la biodiversidad y el cuidado del medio ambiente. 
Todas las iniciativas públicas deben ser analizadas y evaluadas en relación al impacto social y económico que provocan. Ninguna intervención estatal en el territorio resulta neutral, todas las acciones -e incluso las omisiones- del Estado a través de sus instituciones, planes y programas, reubican a las personas en términos socioeconómicos -y también de géneromodificando las desigualdades existentes en la estructura social, ya sea para paliarlas o, en el peor de los casos, para agudizarlas (Pérez Orozco, 2012). No obstante la importancia que reviste ese conocimiento no hay análisis sobre la política pública respecto de la $\mathrm{AF}$ en Río Gallegos, y tampoco contamos con evidencia empírica sistematizada en relación con ella.

Es por todo esto, que nuestro grupo de investigación se propone como objetivos, en primer lugar, identificar la oferta programática pública del período comprendido entre 2007 - 2017, en la ciudad de Río Gallegos, en relación con la promoción y el sostenimiento de la AF. En segundo lugar, analizarla desde un enfoque de derechos humanos en dos dimensiones: la primera, calificar su pertinencia para alcanzar las metas definidas por el ODS 2: Hambre 0, y, la segunda, determinar la magnitud del esfuerzo que realiza el Estado para cumplir con la obligación de satisfacer el derecho a la alimentación a través del sostenimiento de la AF, tomando como modelo la dimensión o categoría capacidad estatal, propuesta por el Grupo de Trabajo para la medición del Protocolo de San Salvador.

Las preguntas que guían la investigación son: ¿Cuál es la oferta programática en relación con la promoción y sostenimiento de la AF en Río Gallegos? ¿La oferta contempla las metas del ODS 2 Hambre cero, en el cual se encuadra la promoción de la AF? ¿La oferta es pertinente para la progresiva realización del derecho a la alimentación según indicadores de cumplimiento de la obligación estatal elaborados por el Grupo de Trabajo para la medición del PSS?

El trabajo se estructura de la siguiente manera: en primer término realizamos algunas aclaraciones conceptuales consideradas pertinentes, y luego desarrollamos la descripción y fundamentación del marco teórico bajo el cual trabajamos. Después, presentamos los resultados obtenidos en la investigación, con el soporte de cuadros y tablas de elaboración propia, con la intención de facilitar la exposición. A continuación proponemos nuestra interpretación y análisis de los datos obtenidos, explicando el significado de los hallazgos realizados desde el enfoque propuesto.

Finalmente presentamos las conclusiones a las que arribamos luego de contrastar la oferta programática con las metas del ODS 2 y medirla a partir de los indicadores de capacidad estatal, lo cual nos permite sostener que se trata de una política pertinente con las obligaciones derivadas de los pactos internacionales de derechos humanos y la Agenda de desarrollo 2030, pero restringida al nivel nacional y poco diversa en relación al esfuerzo estatal.

\subsection{Marco de Referencia}

\section{La agricultura familiar en Río Gallegos.}

Agricultura familiar es un término relativamente nuevo que la Organización de las Naciones Unidas para la Alimentación y la Agricultura (FAO) define como " una forma de vida y una cuestión cultural, que tiene como principal objetivo la reproducción social de la familia en condiciones dignas, donde la gestión de la unidad productiva y las inversiones en ella realizadas es hecha por individuos que mantienen entre sí lazos de familia, la mayor parte del trabajo es aportada por los miembros de la familia, la propiedad de los medios de producción (aunque no siempre la tierra) pertenece a la familia, y es en su interior que se realiza la transmisión de valores, prácticas y experiencias" (2018).

En la AF, las relaciones económicas adoptan expresiones particulares, son más inmediatas, personales, flexibles y cambiantes, su escala de producción se ubica geográficamente en el ámbito de "lo local o regional", en la esfera de lo micro-social, y se solapan prácticas productivas con reproductivas, propias de la vida cotidiana de los/as productores, en 
comparación con los complejos agroeconómicos más extensos. Esta particular forma de organización posiciona a la AF dentro del sistema agroalimentario argentino en un lugar específico como sujeto económico, pero vertiendo sobre el cuadro de análisis del sector una multiplicidad de procesos que necesariamente implican una mirada amplia, que trascienda la evaluación economicista basada estrictamente en la ponderación de su utilidad en relación a pérdidas e ingresos, y que por el contrario, lo comprenda en toda su complejidad, involucrando una visión de totalidad en el análisis del sector.

Otra cuestión importante de señalar se refiere al corrimiento de las barreras productivas sin una planificación estratégica en relación con la producción agropecuaria. El crecimiento de las ciudades desplazó a la actividad agropecuaria, provocando su corrimiento hacia la intersección del espacio entre el campo y la ciudad denominado zonas periurbanas.

En estas zonas periurbanas se observan transformaciones tanto en las dinámicas rurales como en las urbanas, produciéndose un fenómeno de interpenetración de ámbitos, en el cual no solo lo rural se impregna de dispositivos y códigos urbanos, sino que en la ciudad se recurre a saberes, valores y dispositivos típicamente rurales. (Cimadevilla y Carniglia, 2008). Por lo tanto, al introducirnos en la dimensión de la AF de una zona periurbana se debe tener presente también su vinculación con aspectos no necesariamente agrícolas, tales como la salud, la educación, los servicios de electricidad, agua y comunicación, producción y comercialización (Vassallo, 2008).

Como se estima que ha sucedido en casi toda la provincia de Santa Cruz, el asentamiento de los pequeños núcleos productivos familiares dentro de las llamadas comúnmente "Zonas de Chacras", verbigracia San Benito (en los '80), Palermo Aike, Los Álamos, Consejo Agrario, resultan ser la expresión, en la realidad, de procesos vinculados con la posesión desigual de la tierra como capital productivo, así como el resultado de decisiones aleatorias de los gobiernos locales para resolver transitoriamente (pero que luego se han perpetuado en el tiempo como respuesta final) los inconvenientes ligados con la planificación y expansión de los límites de urbanización en relación a los límites productivos.

En Santa Cruz los núcleos de AF (NAF) tienen una superficie media de 5 ha, son administrados por personas que en promedio tienen 47 años y son predominantemente agrícolas: se destaca la producción vegetal y animal por sobre las demás actividades productivas como la pesca, la agroindustria o la producción de artesanías (Birgi, 2018). A diferencia de otras regiones del país, las condiciones climáticas de la provincia -clima templado frío, con temperaturas medias de entre $0^{\circ}$ y $12^{\circ}$ (Oliva, González y Rial, 2001) y la intensidad del viento- obligan a los/as productores a proteger los cultivos y seleccionar mejor las especies a implantar. Estos sistemas de producción basados en la mano de obra familiar, se asientan en los límites de la ciudad, generalmente sobre un espacio de tierras áridas, de baja productividad hortícola, y baja disponibilidad y regularidad del recurso agua para la producción de cultivos.

En Río Gallegos, hay 93 NAF relevados por el Registro Nacional de Agricultura Familiar (ReNAF). Aunque la mayoría son propietarios (con tenencia provisoria de la tierra en producción), solo unas pocas familias residen en las unidades prediales porque no cuentan con los servicios básicos (gas y agua). Si bien el ingreso principal de las familias proviene de otras actividades, los NAF son fuente generadora de ingresos. Las principales actividades en las zonas de Chacras son la cría de animales de granja, como aves ponedoras o criollas, y cerdos, destinados fundamentalmente al autoconsumo familiar, y en un bajo porcentaje a la comercialización. La horticultura se encuentra limitada por la escasez y/o falta de acceso al agua.

A pesar de que los sistemas de producción que se están constituyendo dan cuenta de un desarrollo lento, y en cierto grado desorganizado, cabe destacar que en las dos últimas décadas, la producción de alimentos para el autoabastecimiento se ha ido incrementando, lo 
cual significa para muchas familias una alternativa productiva para superar las condiciones socioeconómicas desfavorables potenciando la producción de excedentes como nueva fuente de ingresos.

\section{Las ventajas de un análisis desde la perspectiva de los derechos humanos}

En primer lugar es conveniente explicar la cuestión de ¿por qué analizar las políticas públicas desde un enfoque de derechos humanos? Como sostienen Abramovich y Pautassi (2009) en Argentina, y también en el resto de América Latina, se viene construyendo un consenso cada vez mayor sobre la necesidad de pensar las políticas públicas como obligaciones estatales para el cumplimiento de los derechos humanos. Este consenso, explican les autores, ha sido impulsado por el litigio judicial, basado fundamentalmente en la operatividad de las cláusulas constitucionales, lo cual fue promoviendo la reflexión acerca de cómo se pueden articular el campo de los derechos humanos con el campo de las políticas públicas.

Luego del fracaso de las políticas focalizadas, fuertemente ancladas en la idea del asistencialismo, que fueron promovidas por los organismos de crédito internacional agrupados en el consenso de Washington- allá por los años ' 80 y '90, comenzó a incorporarse la retórica de los derechos humanos a las recomendaciones de esos mismos organismos internacionales para el diseño de las políticas públicas (Abramovich y Pautassi, 2009). Sin embargo el consenso en el discurso no significa automáticamente consenso en las prácticas y las estrategias políticas. Así, el diseño de las políticas muchas veces siguió respondiendo a la focalización y al asistencialismo sin dejarse permear verdaderamente por el enfoque de derechos humanos. Como dice Abramovich (2006) "el campo de las políticas sociales y las estrategias de desarrollo y el campo de los derechos humanos han corrido en paralelo, con pocos puntos de encuentro o conexión" (p. 13).

El derecho internacional ha avanzado considerablemente en la fijación de estándares y principios para el monitoreo del cumplimiento de los derechos, lo cual resulta de "inestimable valor para ajustar aquellas discusiones acerca de la universalidad, transparencia e institucionalidad de las políticas sociales" (Abramovich, 2006, p. 14). Los órganos de supervisión internacional de los derechos humanos resultan fundamentales para mostrar el camino por donde analizar las políticas públicas, ya que pueden servir de guía para saber qué aspectos observar, gracias a su tarea de elaboración de estándares y principios de fiscalización cada vez más precisos y claros (Abramovich y Pautassi, 2009).

Por ejemplo, el SIDH tiene un instrumento jurídico vinculante: el Protocolo Adicional a la Convención Americana sobre Derechos Humanos en materia de Derechos Económicos Sociales y Culturales, más conocido como Protocolo de San Salvador (PSS). Este Protocolo establece las obligaciones relativas al cumplimiento de los derechos económicos, sociales y culturales, y a fin de avanzar en el monitoreo de la realización de los derechos, la Asamblea de la OEA constituyó un Grupo de Trabajo (GT) para analizar los informes nacionales previstos por el Protocolo y para establecer los lineamientos generales y elaborara indicadores precisos para orientar a los Estados en sus obligaciones.

Para la elaboración de indicadores primero es necesario definir qué se entiende por cada derecho (obligación contenida en la norma) y entonces establecer las dimensiones o categorías conceptuales (estándares) que permitirán elaborar los indicadores (Pautassi, 2010). El GTPSS define tres dimensiones o categorías conceptuales: recepción del derecho, contexto financiero y compromiso presupuestario, y capacidades estatales; y tres principios transversales: igualdad y no discriminación, acceso a la justicia y acceso a la información y participación (2015). En este trabajo consideramos la categoría capacidad estatal, porque permite apreciar el grado de utilización de los recursos disponibles del Estado en la asistencia a la AF. 
Teniendo en cuenta que la satisfacción de los derechos exige la aplicación de políticas y acciones de gobierno, en septiembre de 2015 los Estados miembro de la ONU se comprometieron con una Agenda de Desarrollo para el año 2030. Esta Agenda fija 17 Objetivos de Desarrollo Sostenible (ODS) que aunque no son jurídicamente obligatorios, instalaron en las agendas de gobierno la responsabilidad de atacar las causas de la pobreza y la desigualdad. Los 17 ODS abarcan tres dimensiones: crecimiento económico, inclusión social y protección del medio ambiente. En este trabajo tomamos el ODS 2: Hambre 0 que se encuentra directamente relacionado con el derecho a la alimentación adecuada, la sostenibilidad de la producción agrícola, la biodiversidad y la protección del medio ambiente, como se mencionó anteriormente. Contrastar la oferta de programas con las metas propuestas por el ODS 2 permite calificar la orientación de las políticas en relación con el desarrollo sostenible.

\subsection{Resultados, análisis y discusión Metodología de abordaje}

Se realizó un estudio de tipo exploratorio/descriptivo que comenzó con un sondeo sobre el sector, que incluyó una revisión de folletería, cartillas técnicas, exploración de sitios web de las instituciones involucradas con la AF y diálogo con técnicos/as del INTA y la ex Secretaría de AF (SAF). A partir de la información obtenida, seleccionamos cinco programas relevantes y en vigencia para el período 2007 - 2017: ProHuerta, Buenas Prácticas Agrícolas, Registro Nacional de Agricultura Familiar (ReNAF), Sello Producido por la AF y Monotributo Social Agropecuario. Para completar el panorama de la oferta pública, le sumamos a este grupo la Ley Nacional 27.118 de Reparación Histórica de la AF.

A continuación realizamos el fichaje de cada programa registrando en una planilla estándar los siguientes elementos: temporalidad, nivel territorial -nacional, provincial o municipalorigen del financiamiento - nacional, provincial o municipal- objetivos y órgano de aplicación responsable. Esto nos ayudó a sistematizar la información.

Para medir la categoría capacidad estatal, definimos tres dimensiones: institucional, administrativa y política, y para cada una de ellas definimos al menos un indicador, siguiendo el modelo propuesto por el GTPSS, como se muestra en la Tabla 1.

Tabla 1 - Capacidad estatal

Categoría Dimensión

\begin{tabular}{|c|c|c|}
\hline Categoría & Dimensión & Indicadores \\
\hline \multirow[b]{2}{*}{$\begin{array}{l}\text { Capacidad } \\
\text { estatal }\end{array}$} & & Cantidad de dependencias públicas dedicadas a la $\mathrm{AF}$ \\
\hline & Institucional & $\begin{array}{l}\text { Existencia en la Constitución, o alguna Ley, que establezca } \\
\text { como prioridad el desarrollo de la AF }\end{array}$ \\
\hline $\begin{array}{l}\text { Qué } \\
\text { capacidad } \\
\text { institucional, } \\
\text { administrativa }\end{array}$ & Administrativa & $\begin{array}{l}\text { Existencia de un censo agropecuario que permita monitorear } \\
\text { al sector }\end{array}$ \\
\hline $\begin{array}{l}\text { y politica } \\
\text { tiene el }\end{array}$ & & Cantidad de programas de promoción a la $\mathrm{AF}$ \\
\hline $\begin{array}{l}\text { Estado para } \\
\text { asistir a la } \\
\text { AF) }\end{array}$ & Política & $\begin{array}{l}\text { Cantidad de población efectivamente cubierta por algún } \\
\text { programa de promoción a la AF }\end{array}$ \\
\hline
\end{tabular}

El análisis documental nos permitió obtener los datos para los indicadores definidos. Fue fundamental para nosotras acceder a los resultados censales del Registro Nacional de Agricultura Familiar (ReNAF) ya que estar registrado en el ReNAF es un requisito excluyente 
para acceder al resto de los programas destinados al sector. Según nuestros/as informantes no hay productores familiares no registrados en el ReNAF. Manejar este dato nos permitió asegurar con certeza la cantidad de población efectivamente cubierta por al menos un programa de promoción a la AF. Estar registrado en el ReNAF es sinónimo de haber sido alcanzado por un programa específico: el censo del sector.

Además, para completar el testeo de las dimensiones Institucional y Política a fin de acceder a algunas percepciones de los/as agricultores de nuestra localidad fuimos en busca de sus opiniones, con la intención de sondear, de modo aproximativo, lo que piensan con respecto a la política de la AF. Para ello elaboramos una encuesta anónima cuyo modelo se encuentra en el ANEXO y que tuvo un carácter semiestructurado ya que al ir relevando a cada entrevistado/a pudimos obtener información cualitativa que nos permitió recuperar más detalle en torno a cómo perciben por ejemplo el rol del Estado en el desarrollo de su actividad.

La Tabla 2 resume los principales elementos del diseño metodológico utilizado:

\section{Tabla 2 - Diseño Metodológico}

\begin{tabular}{ll}
\hline \multicolumn{1}{c}{ Diseño Metodológico } \\
\hline Tipo de estudio & descriptivo / exploratorio \\
\hline Universo de estudio & Política pública para la AF en Río Gallegos 2007-2017 \\
\hline Unidad de análisis & Programas referidos a la AF en Río Gallegos 20017 - 2017 \\
\hline Unidad de observación & $\begin{array}{l}\text { Objetivos enunciados en los programas, texto de la Ley, opinión de } \\
\text { las/os agricultores }\end{array}$ \\
\hline & $\begin{array}{l}\text { Para la selección de los programas se usó el tipo de muestra } \\
\text { intencional: estrategia de muestreo no probabilístico, que incluyó } \\
\text { los casos considerados como más interesantes. } \\
\text { Para la selección de las/os agricultores se usó el muestreo aleatorio } \\
\text { simple: estrategia de muestreo probabilístico que consistió en la } \\
\text { selección al azar de agricultoras/es para encuestar. }\end{array}$ \\
\hline \multirow{3}{*}{ Técnicas } & $\begin{array}{l}\text { Análisis documental (programas); } \\
\text { Entrevistas y contacto con referentes técnicos/as }\end{array}$ \\
& Encuesta semiestructurada para sondeo de percepción \\
\hline Instrumentos & $\begin{array}{l}\text { Ficha de revisión de documentos } \\
\text { Guía de preguntas para entrevista } \\
\text { Cuestionario de encuesta }\end{array}$ \\
\hline Análisis de los datos & $\begin{array}{l}\text { Determinar la cantidad de metas del ODS } 2 \text { contempladas por los } \\
\text { programas. } \\
\text { Identificar de qué manera la oferta pública en su conjunto responde } \\
\text { a la obligación estatal para el cumplimiento efectivo del derecho } \\
\text { humano a la alimentación a través del sostenimiento de la } \\
\text { agricultura familiar, a partir de indicadores de capacidad estatal, } \\
\text { como los propuestos por el GT para la medición del PSS }\end{array}$ \\
\hline
\end{tabular}

\section{Resultados}

Programas y actividades en Río Gallegos

En primer lugar, presentamos una breve caracterización de los programas a considerar y las actividades realizadas por los organismos responsables:

El ReNAF fue creado en 2007 y a través de la inscripción de los/as agricultores familiares buscó visibilizar y fortalecer su trabajo, facilitando el acceso prioritario a diversos beneficios: previsionales e impositivos, financieros y de inversión, asistencia técnica y capacitación, y comercialización, así como a los derechos consagrados en la Ley Nacional 27.118 de 
Reparación Histórica de la Agricultura Familiar. La información obtenida contribuye también a que las políticas públicas sobre tierras, acceso al agua, apoyo a la producción y a la comercialización y de infraestructura, lleguen de forma coordinada y efectiva al sector.

El órgano de aplicación es la ex Secretaría de Agricultura Familiar (SAF), recientemente disminuida de rango a Subsecretaría de Agricultura Familiar y Desarrollo Territorial. Según nuestras informantes clave, la oficina llegó a contar con ocho integrantes en toda la provincia, siendo cuatro los dedicados a Río Gallegos. Ellos/as realizaron las tareas de registro y carga de los datos, en colaboración con otros/as técnicos/as de INTA que trabajaban en el marco del ProHuerta en esa institución. Esta experiencia permite apreciar los particulares vínculos existentes en Río Gallegos entre las instituciones dedicadas la AF en torno al gran programa nacional ProHuerta.

La SAF también realizó las capacitación de registradores y cargadores de datos para ReNAF; realizó las Jornadas de Registro de Productores Familiares; el asesoramiento e inscripción para el Monotributo Social Agropecuario (MSA); el asesoramiento y gestión del Sello "Producido por la AF"; se dedicó a la organización de Ferias productivas y exposición de productos, así como de intercambio de semillas, en estrecho vínculo de trabajo con el INTA; y visitó periódicamente a los NAF, brindando asesoramiento en el terreno y acompañamiento para cualquier tipo de trámite en relación con la actividad; organizó talleres y charlas de capacitación a productores; y, distribución de semillas.

El ProHuerta nació en 1990 y hasta la actualidad es uno de los programas sociales nacionales más importantes para la producción y el desarrollo de una agricultura orientada al autoabastecimiento y la comercialización de alimentos agroecológicos. Los organismos de aplicación son el INTA y el ex Ministerio de Desarrollo Social -actualmente fusionado Ministerio de Salud y Desarrollo Social- Este programa interactúa con más de 3 millones de personas, articula en el territorio con más de 10 mil instituciones y organizaciones, y forma parte de más de 400 ferias agroecológicas.

$\mathrm{Su}$ estructura y funcionamiento son complejos. El financiamiento es nacional, proviene del ex Ministerio de Desarrollo Social, es gestionado por el INTA a través de la Fundación ArgenINTA $^{1}$. En el período analizado el ProHuerta alcanzó a tener hasta seis técnicos/as en Río Gallegos de los cuales uno era coordinador del programa. Dentro de la estructura de INTA el ProHuerta funciona con autonomía, es el único programa que posee logo propio lo cual le otorga visibilidad e independencia respecto al resto de las áreas de INTA. No obstante esta autonomía, el programa reviste la siguiente particularidad que, como se verá, tiene llamativas consecuencias: las actividades que lleva adelante también convocan a técnicos/as de otras áreas, en especial a los/as de la Agencia de Extensión Rural, Forestales o Producción animal, con lo cual existe un solapamiento de estructuras y convergencia de tareas técnicas. Esto además se ve favorecido porque en Río Gallegos el ProHuerta funciona en la sede de la Estación Experimental Agropecuaria Santa Cruz donde también lo hace la Agencia de Extensión Rural Rio Gallegos.

Entre las actividades del ProHuerta en Río Gallegos podemos mencionar:

- Entrega de aves (pollitas ponedoras a familias)

- Entrega de árboles frutales.

- Distribución de semillas.

- Organización de reuniones y talleres con productores.

- Asesoramiento en el terreno a productores familiares.

- Charlas y asesoramiento para huertas escolares.

\footnotetext{
${ }^{1}$ La Fundación ArgenINTA fue creada en 1993 por el INTA para articular las relaciones entre lo público y lo privado (ejecutando programas y proyectos, y brindando apoyo técnico y económico a las iniciativas productivas).
} 
- Capacitaciones y talleres de variado tipo en relación a las actividades que se desarrollan en la localidad, por ejemplo: huerta orgánica; multiplicación de semillas aromáticas; cría de gallinas ponedoras; construcción de invernaderos; conocimientos básicos y alternativas de producción, manejo, conservación y comercialización de productos para la comercialización; huerta agroecológica; técnicas de poda de diversas plantas, realización de almácigos de huerta, multiplicación, almacenamiento y conservación de semillas para siembra a partir de frutos; producción de árboles a partir de estacas; elaboración de dulces artesanales y conservas.

- Organización de Ferias productivas y exposición de productos familiares.

- Organización de Ferias de intercambio de semillas.

- EXPOHUERTA.

- Asesoramiento y acompañamiento para la organización de la Asociación de Productores Frutihortícolas y Afines de Río Gallegos.

- Relevamiento y registro de productores familiares (colaboración con la SAF)

- Elaboración, diseño y distribución de cartillas de información técnica de interés para el sector.

La convergencia de las tareas y la ubicación espacial-institucional del programa favoreció el ingreso de varios/as técnicos/as a la planta permanente de INTA desde la plataforma de contratación que supuso el ProHuerta. Es decir que una vez contratados en ProHuerta el trabajo desempeñado favoreció el aprovechamiento de las oportunidades para entrar en el INTA. Lo notable es que en la actualidad cuando se produce la vacancia en el ProHuerta por ingreso de un técnico/a a INTA los contratos del programa no están siendo renovados. Como resultado, en la actualidad las personas contratadas por el programa de redujeron a dos -de seis puestos que había llegado a tener el programa en el período observado-. Según la información brindada por el informante clave a quien consultamos, paulatinamente fueron dejando de realizarse algunas actividades tales como entrega de árboles frutales, mermó la frecuencia de las capacitaciones, se espació considerablemente la organización de Ferias productivas y exposición de productos y no se realizaron más EXPOHUERTA (no hubo ninguna en 2018, ni está pensada ninguna para 2019). Esto nos permitió observar la limitación práctica de la implementación del programa en la actualidad en relación con el período observado dada la no renovación de las vacancias producidas y la reducción de las actividades realizadas.

El Programa Buenas Prácticas Agrícolas (BPA) comenzó en 2008 y se extendió hasta 2018 cuando se convirtió en Buenas Prácticas Agrícolas Sustentables (BPAS). Este cambio, aunque no generó ningún costo fiscal, pasó el Programa a la órbita de la Secretaría de Agricultura, Ganadería y Pesca (ex Ministerio) y a la Secretaría de Alimentos y Bioeconomía, que lo orientó a acciones vinculadas al incremento del valor agregado, a la asistencia y capacitación para mejorar la calidad, sanidad y productividad, a la integración entre eslabones y a la promoción de sus productos.

El organismo de aplicación es el SENASA. Según la información obtenida en la entrevista a las referentes de la oficina en Río Gallegos pudimos saber que el programa no registra actividad en la localidad. La explicación que nos dieron para tal situación es que, según su apreciación, la población dedicada a la AF es muy pequeña, ínfima, poco relevante desde el punto de vista del volumen de producción. Sí registran algunas inscripciones en el Registro Nacional Sanitario de Productores Agropecuarios (RENSPA) de algunos pequeños productores que presumiblemente se dedican a la $\mathrm{AF}$, pero que no están identificados como tales específicamente.

Manifestaron que el trabajo en relación a la AF está concentrado, mayormente, en las actividades del ProHuerta y que alguna vez intentaron trabajar en conjunto con este programa 
pero que no pudieron hacerlo ya que les resultó imposible sortear el "recelo" que esgrimía el técnico coordinador del programa para socializar la información sobre el sector. Esta desconfianza resultó ser un gran obstáculo para la generación de estrategias conjuntas.

Reconocieron también, que por la tradición histórica del organismo acostumbrado a trabajar con el productor de mediana y gran escala, considerar el trabajo con el pequeño productor demanda un esfuerzo de reacomodamiento institucional que lleva su tiempo. A la vez, reconocen la necesidad del acompañamiento a todos los/as productores, sin importar la escala de producción, ya que el control sanitario no admite distinciones entre uno y otro, y una plaga, bacteria o virus afecta tanto a una producción como a otra y acrecienta el riesgo de propagación.

El Monotributo Social Agropecuario (MSA) se implementó en 2009 para incorporar a la economía formal a un sector históricamente vulnerable y excluido. Permitió que por primera vez y sin costo muchas/os agricultores pudieran emitir facturas, acceder a la jubilación, a una obra social y a la exención del pago de Ingresos Brutos. En 2018 el gobierno nacional modificó el Régimen tributario (finalizó el acuerdo entre el Ministerio de Desarrollo y MINAGRO, con lo cual se dio de baja el MSA), y se exigió a las/os agricultores una constancia formal que justifique la actividad económica para transferirlos al Monotributo Social durante 2019, pero ahora pagando el $25 \%$ ya que solamente el $75 \%$ del beneficio sería cubierto por el Estado. El órgano de aplicación era la ex SAF, cuya actividad estaba específicamente ligada al sector, pero actualmente es el ANSES.

El Sello "Producido por la Agricultura Familiar" fue creado en 2015 en el ámbito del MERCOSUR para que las/os consumidores identifiquen los productos de la AF, fomentando el consumo de alimentos frescos y saludables, y para fortalecer a las economías regionales. El órgano responsable del sello es la ex SAF. Ante la consulta por la efectiva utilización del sello en la actualidad, nos encontramos con que no se está promoviendo su utilización.

Programas y ODS 2: Hambre 0

La Tabla 3 muestra los objetivos generales de cada programa en relación con las 7 Metas del ODS $2 .^{2}$

2 Por razones de espacio no reproducimos aquí cada una de las Metas del ODS 2, pero las mismas se encuentran resumidas en un cuadro en el ANEXO 2, y también están disponibles en: 
Tabla 3 - Programas y ODS 2

Programas AF en Río Gallegos (2007 - 2017) y relación con ODS 2: Hambre 0

Poner fin al hambre, lograr la seguridad alimentaria y la mejora de la nutrición y promover la agricultura sostenible.

\begin{tabular}{|c|c|c|}
\hline Programa & Objetivos generales & Metas \\
\hline \multirow{7}{*}{ ProHuerta } & 1. Mejorar y diversificar la alimentación de las familias, escuelas, & 2.1 \\
\hline & $\begin{array}{l}\text { instituciones y organizaciones de la comunidad. } \\
\text { 2. Promover la participación comunitaria en la producción de alimentos. }\end{array}$ & $\frac{2.2}{2.1}$ \\
\hline & & 2.3 \\
\hline & 3. Incentivar la formacion y difundir tecnologias apropiadas para la & 2.4 \\
\hline & & 2.5.a \\
\hline & $\begin{array}{l}\text { 4. Multiplicar alternativas de comercialización que puedan integrarse en un } \\
\text { mercado de economía social. }\end{array}$ & 2.5.c \\
\hline & 5. Mejorar el ingreso familiar. & 2.3 \\
\hline \multirow[t]{3}{*}{ BPA } & $\begin{array}{l}\text { 1. Reducir los riesgos de contaminación físicos, químicos y biológicos en la } \\
\text { producción primaria, así como el acondicionamiento a campo, pos-cosecha, } \\
\text { transporte y almacenamiento de los alimentos. }\end{array}$ & $\begin{array}{l}2.3 \\
2.4\end{array}$ \\
\hline & Pronicior la nroducción suctentable & 2.3 \\
\hline & 2. Propiciar la produccion sustentable & 2.4 \\
\hline \multirow[b]{3}{*}{ RENAF } & 1. Visibilizar y fortalecer el trabajo de Agricultores y Agricultoras & 2.3 \\
\hline & Familiares en todo el país. & 2.4 \\
\hline & $\begin{array}{l}\text { 2. Permitir al acceso de forma prioritaria a programas y proyectos para el } \\
\text { sector y a los derechos consagrados en la Ley de Reparación Histórica de la } \\
\text { Agricultura Familiar } 27.118 \text {. }\end{array}$ & $\begin{array}{l}2.3 \\
2.4\end{array}$ \\
\hline MSA & $\begin{array}{l}\text { 1. Facilitar y promover la incorporación a la economía formal de aquellas } \\
\text { personas en situación de vulnerabilidad que han estado históricamente } \\
\text { excluidas de los sistemas impositivos y de los circuitos económicos. }\end{array}$ & 2.3 \\
\hline $\begin{array}{l}\text { Sello } \\
\text { "Producido } \\
\text { por la AF" }\end{array}$ & $\begin{array}{l}\text { 1. Identificar, destacar y promocionar la variedad y calidad de los productos } \\
\text { (agroalimentarios y artesanías) y puntos de venta de la Agricultura Familiar } \\
\text { y Economía Social, destacando sus atributos culturales, su producción } \\
\text { personalizada en la elaboración, transformación, agregado de valor y } \\
\text { comercialización. }\end{array}$ & $\begin{array}{c}2.3 \\
2.5 \cdot \mathrm{b}\end{array}$ \\
\hline
\end{tabular}

Fuente: elaboración propia

La Tabla 4 muestra la Capacidad estatal comprometida con la promoción de la AF según los indicadores definidos para las tres dimensiones antes establecidas.

Tabla 4 - Capacidad estatal

\begin{tabular}{ll} 
Dimensión & Indicador \\
\hline & - 6 dependencias públicas dedicadas a la AF: 3 nacionales: \\
& INTA, SAF y SENASA, 2 provinciales: Ministerio de la \\
& Producción e industria de la Pcia. de Santa Cruz y Consejo \\
Institucional & $\begin{array}{l}\text { Agrario Pcial.; y, } 1 \text { municipal: Secretaría de desarrollo } \\
\text { comunitario de la Municipalidad de RG. }\end{array}$
\end{tabular}

\begin{tabular}{cll}
$\begin{array}{c}\text { Capacidad } \\
\text { estatal }\end{array}$ & -Ley Nacional 27.118 de Reparación Histórica de la AF. \\
\cline { 2 - 3 } & Administrativa & - Censo Nacional de agricultores/as: el ReNAF \\
\cline { 2 - 3 } & & - 5 programas nacionales referidos la AF: ProHuerta, BPA, \\
& MSA, ReNAF, Sello "Producido por la AF". \\
Política & - la población efectivamente cubierta por algún programa es \\
& $\begin{array}{l}114 \text { agricultoras/es inscriptos en el ReNAF, correspondientes } \\
\text { a 93 NAF }{ }^{(*)} \text {. }\end{array}$
\end{tabular}

Fuente: elaboración propia 
${ }^{(*)}$ Podemos manejar este dato con absoluta certeza ya que el número se desprende de la inscripción en el ReNAF, lo cual significa que al estar efectivamente inscriptas en el ReNAF esas personas han sido alcanzadas como mínimo por esta política censal pensada especialmente para el sector. Además el requisito de la inscripción es fundamental para el acceso a cualquiera de los programas pensados para el sector de la AF. Es por ello que fue sobre este universo de 93 NAF sobre el cual pensamos realizar el sondeo de las percepciones de los/as agricultores con respecto a la política de AF en Río Gallegos.

\section{Algunas percepciones de los/as agricultores.}

Como adelantamos, para completar la observación del esfuerzo estatal con el sostenimiento y promoción de la $\mathrm{AF}$, elaboramos una encuesta anónima que nos permitió conversar con algunos/as agricultores y aproximarnos a algunas de sus percepciones.

Nos contactamos con 25 productoras/es de 93 NAF acreditados por el ReNAF en Río Gallegos, para preguntarles sobre la política de $\mathrm{AF}^{3}$

En muchos casos, las preguntas de la encuesta dispararon la conversación más allá del cuestionario, y ese diálogo reveló la misma dirección en una serie de comentarios que podríamos agrupar bajo el título sensación de abandono. Las expresiones registradas fueron: "El INTA siempre nos acompañó"; "Antes, cuando estaba el coordinador, era distinto" "; "Iba a todas las reuniones y talleres que hacían"; "El INTA siempre estuvo, siempre me ayudó", "Antes era distinto".

Estas manifestaciones nos permitieron aproximarnos a la forma en la que, desde el punto de vista de los/as productores familiares consultados, fue cambiando el acompañamiento de los/as técnicos/as en el terreno, haciendo que el recuerdo del apoyo vivido en un tiempo pasado se idealice cada vez más a partir de la percepción del contacto esporádico del presente. Las Figuras 1 a 5 muestran los resultados obtenidos.

\section{Figura 1 - Sexo de las/os encuestadas/os}

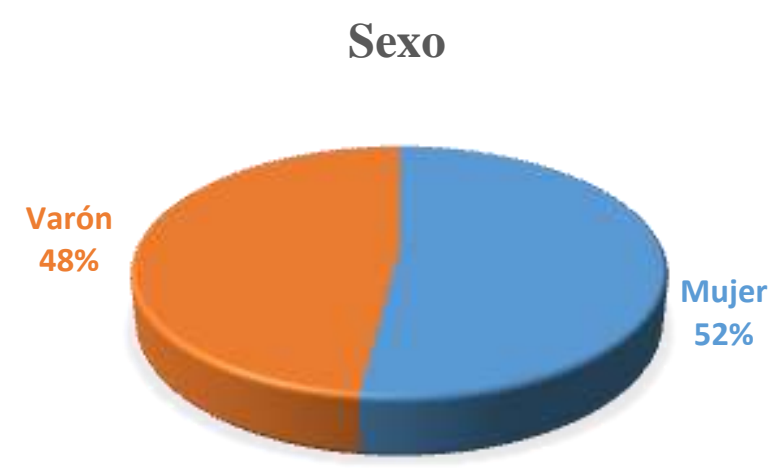

Fuente: elaboración propia

\footnotetext{
${ }^{3}$ Para la definición de la muestra de 25 casos utilizamos la siguiente fórmula:

$$
\frac{\frac{z^{2} \times p(1-p)}{e^{2}}}{1+\left(\frac{z^{2} \times p(1-p)}{e^{2} N}\right)}
$$
}

Con un nivel de confianza del $75 \%$ y un margen de error del 10\%. Estos valores en el relevamiento de las percepciones de los/as productores se consideran suficientes para complementar la reflexión en torno al análisis de la oferta programática vigente.

${ }^{4}$ La expresión se refiere al coordinador del ProHuerta. 
Todas/os las/os consultadas/os se dedicaban a la actividad productiva en el período seleccionado. Las diversas actividades que se realizan fueron agrupadas en tres grandes dimensiones siguiendo el modelo del ReNAF, y obviando, en esta oportunidad, las subactividades específicas que dentro de cada una de ellas existen: Producción animal, Producción vegetal y Producción Agroindustrial (con agregado de valor). La mayoría se dedica a la Producción vegetal aunque no de manera exclusiva, ya que muchos NAF realizan al menos dos tipos de actividades.

\section{Figura 2-Actividad productiva}

¿Cuál es la actividad productiva a la que se dedica?

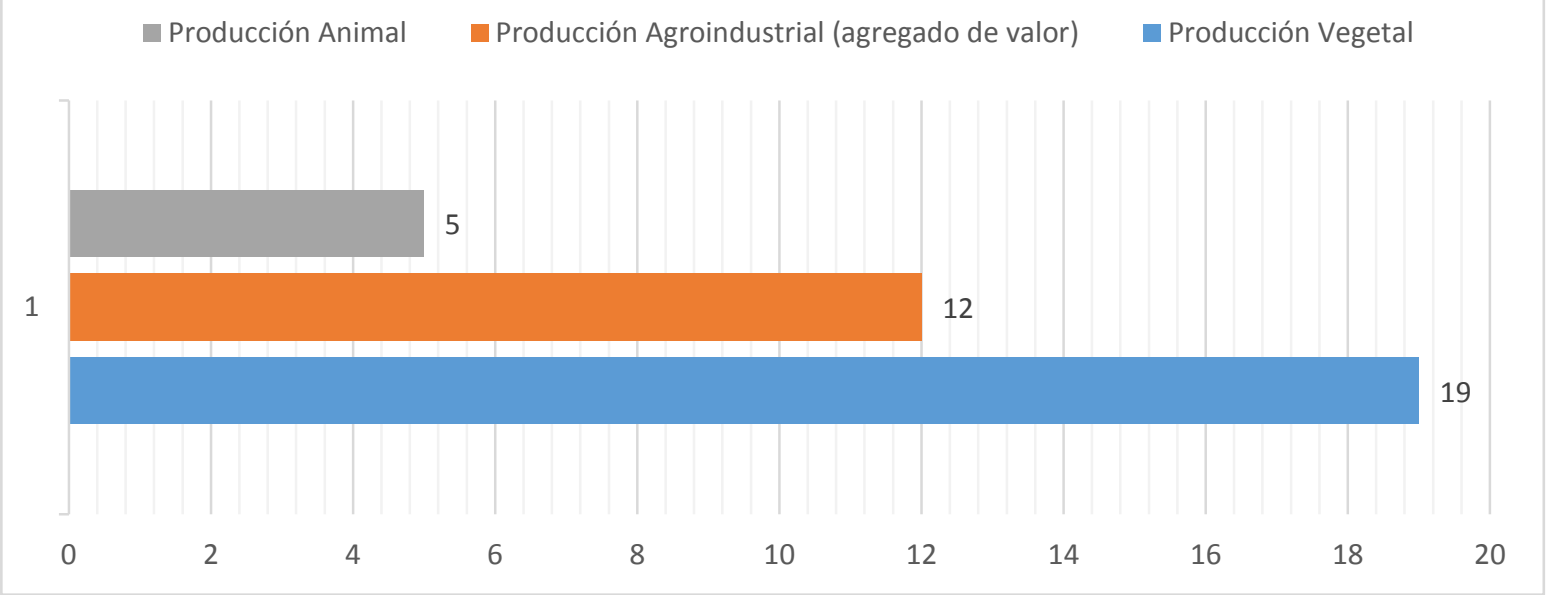

Fuente: elaboración propia

El programa más conocido del sondeo resultó ser el ProHuerta, y el menos conocido el BPA así como la Ley de Reparación Histórica de la AF.

\section{Figura 3 - Programas de la AF}

¿Conoce alguno de los siguientes Programas referidos a la AF?

$$
\square \mathrm{SI} \quad \mathrm{NO}=\mathrm{NS} / \mathrm{NC}
$$

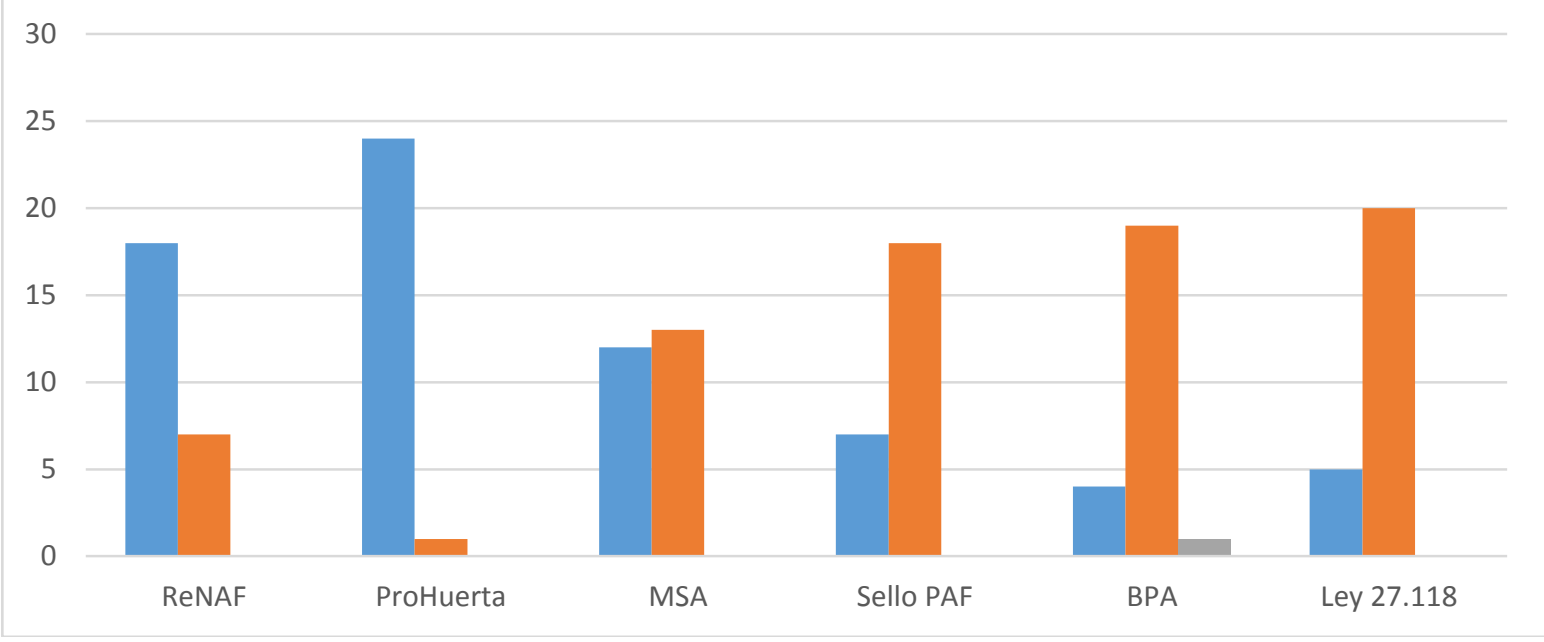

Fuente: elaboración propia

Conocer algún programa en particular no necesariamente significa ser partícipe de este. Varias encuestadas/os manifestaron conocer la existencia de algunos programas gracias a la televisión o a internet aunque nunca fueron alcanzados por su cobertura. La participación en cada uno está ilustrada en la Figura 4. 


\section{Figura 4 - Participación en Programas}

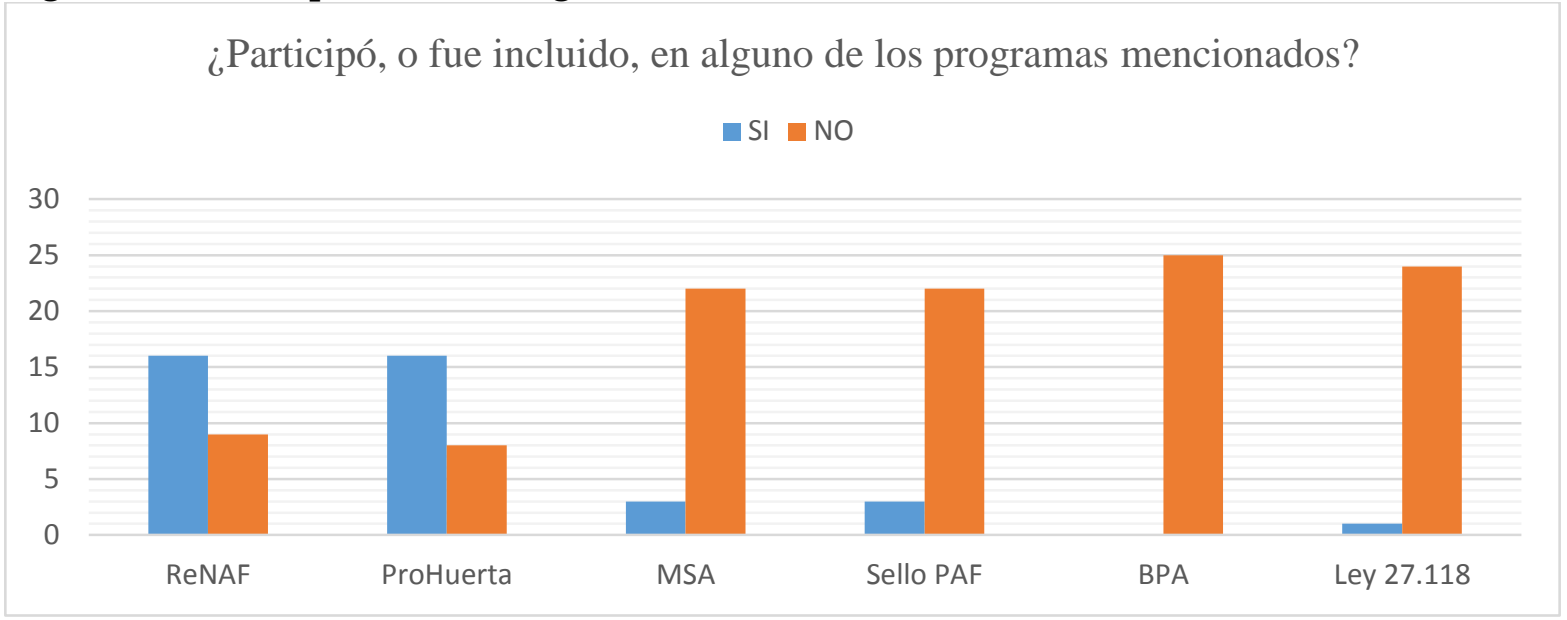

Fuente: elaboración propia

En la última pregunta de nuestra encuesta les pedimos que indicaran cuál de las instituciones involucradas con la AF habían colaborado con el NAF en alguna forma, ya sea con charlas, asistencia técnica, visitas al establecimiento, registros, donación de suministros, etc. Las respuestas se muestran en la Figura 5.

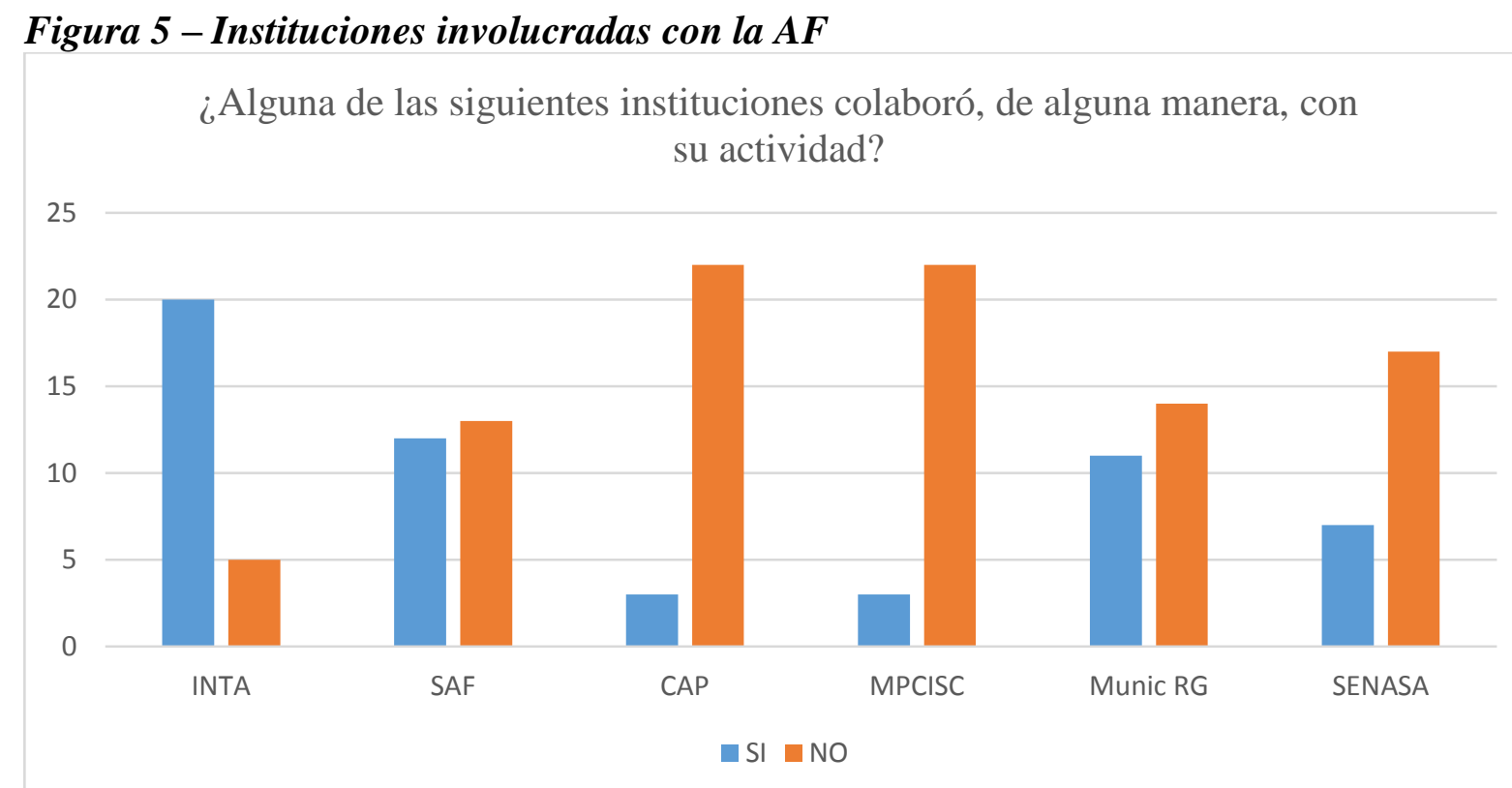

Fuente: elaboración propia

\section{Discusión}

A partir de los datos obtenidos se puede observar que la oferta de programas para la AF en Río Gallegos período 2007-2017, resulta totalmente pertinente con las Metas del ODS 2, ya que todos los objetivos de todos los programas contemplan y se orientan a la consecución de al menos una Meta del objetivo.

Al desagregar la información por año, como muestra la Figura 6, se puede ver que la oferta en su conjunto, contempla casi la totalidad de las Metas del ODS 2 en el período 2007-2014 (85.7\%), y la totalidad de las mismas en el período 2015-2017, momento en el que se sumó al conjunto de programas ya existente (ProHuerta, ReNAF, MSA, BPA) la implementación del Sello "Producido por la AF". Este programa permitió "cubrir", al menos parcialmente, la Meta 2.5 b que no estaba relacionada con ninguno de los objetivos de los anteriores 
programas. Esta Meta apunta a corregir y prevenir las restricciones y distorsiones comerciales en los mercados agropecuarios mundiales, en tanto que el Sello se propone destacar y promocionar la variedad y calidad de los productos (agroalimentarios y artesanías) y puntos de venta de la AF contribuyendo a su comercialización

Desde el 2007 en adelante la tendencia en el número de programas referidos a la atención de la AF ha ido aumentando cada año, comenzando con dos programas hasta llegar a cinco en 2015, mientras que el número de Metas contempladas se mantuvo estable durante esos años. Esto significa que en adecuación a la orientación del desarrollo propuesto por la Agenda 2030 se fueron sumando programas que fortalecieron la oferta pública configurando un conjunto "robusto" de políticas de sostenimiento a la AF. Esta tendencia sufre una abrupta caída en 2018, año que se encuentra fuera de nuestro recorte temporal pero que incluimos especialmente porque da cuenta del cambio con respecto a la orientación registrada en el período de estudio.

\section{Figura 6 - Programas y Metas ODS 2 por año}

Fuente: elaboración propia

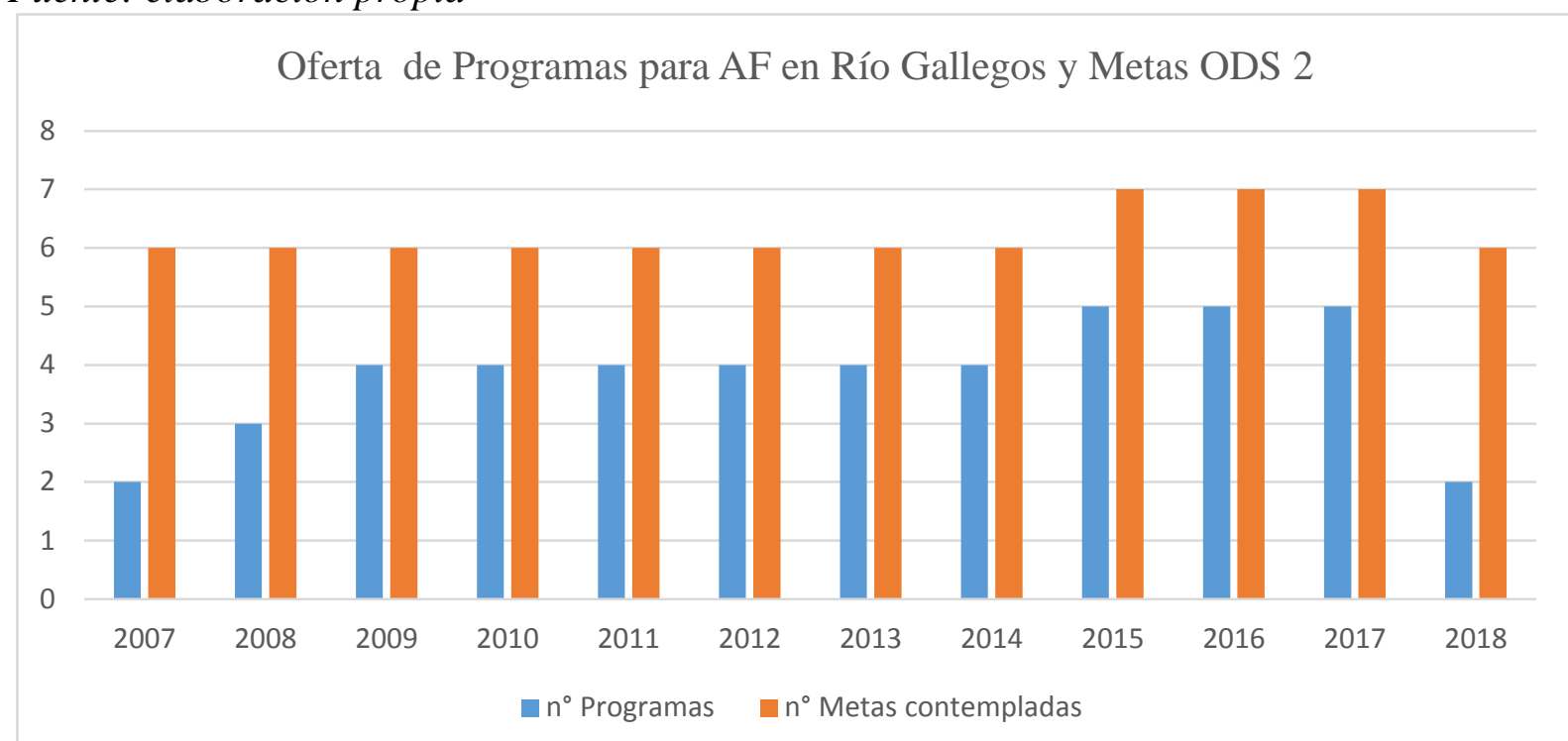

En relación a la Capacidad estatal comprometida con la AF hay que mencionar que a primera vista el esfuerzo ha permeado la Institucionalidad del Estado, ya que existen dependencias específicas dedicadas a la AF en el organigrama estatal (6 en total) y existe una Ley Nacional que indica que la AF es una cuestión prioritaria para el Estado.

Sin embargo, al contrastar esto con las percepciones y opiniones de las/os productores, vemos que dos dependencias públicas, ambas de nivel provincial, no son reconocidas por estos protagonistas como colaboradoras con su actividad: el Consejo Agrario Provincial (CAP) y el Ministerios de la Producción Comercio e Industria de la Provincia de Santa Cruz (MPCISC). En el caso del CAP solamente un encuestado lo identificó, y en el caso del MPCISC ninguno. Por lo tanto, en todo caso la Capacidad estatal comprometida, correspondiente a la dimensión institucional, es de nivel nacional, y no tanto provincial. En relación con esto, las instituciones más reconocidas y valoradas positivamente son nacionales: el INTA y la SAF, les sigue en importancia la Municipalidad de Río Gallegos, sobre todo con la organización de las Ferias productivas locales para ocasiones especiales, como el aniversario de la ciudad, por ejemplo. Por otro lado, si bien la Ley Nacional 27.118 fue sancionada en 2014 aún no fue reglamentada, lo cual significa que no está en vigencia. Tampoco existe ninguna Ley provincial para el sector, con lo cual el compromiso institucional del Estado con el sostenimiento de la AF resulta más débil de lo que a primera vista parece. 
Nos sorprendió que la mayoría de las/os consultadas/os no conoce la Ley. Solamente dos personas la reconocieron pero llamativamente una de ellas no siente aludida por su protección. Queremos detenernos en este punto que es de especial importancia para nosotras, ya que como dicen Abramovich y Pautassi, consideramos que las personas son titulares de derechos, no personas con necesidades, por lo tanto los Estados están obligados a la satisfacción de esos derechos, que pueden ser exigibles por sus titulares (2009). Al inicio de este documento hemos dejado bien en claro que las políticas de sostenimiento y promoción de la AF se derivan del compromiso con el Sistema Internacional de Derechos Humanos, y que no se trata de políticas coyunturales de un gobierno más o menos inclinado a favorecer a este sector históricamente vulnerable. Entonces, resulta fundamental para demandar el cumplimiento del derecho que los propios ciudadanos/as agricultores/as se auto-perciban como titulares de ese derecho, y de esta manera, a partir de esta auto-percepción inicial, se abre la posibilidad de convertirse en un factor de poder e influencia en la discusión sobre la orientación de las políticas de AF. Es en este punto donde advertimos una importante falencia de las políticas públicas.

Con respecto a la Capacidad estatal Política, se puede decir que en el diseño de "escritorio" de la política existen 5 programas que apuntalan al sector. Llamativamente, todos son de nivel nacional, ninguno es provincial. El más reconocido por las/os encuestadas/os es el ProHuerta, al que le sigue el ReNAF. Esto coincide con el reconocimiento de las Instituciones responsables de su aplicación, el INTA y la SAF respectivamente, lo cual nos permite inferir que es la bajada de estos programas al territorio lo que favoreció el vínculo de estas instituciones con el sector. A su vez, cabe destacar que son los dos programas más antiguos y permanentes con respecto a los demás durante el período analizado.

\section{CONCLUSIONES}

El contraste entre la oferta de programas públicos de la AF en Río Gallegos y el ODS 2: Hambre 0 revela la pertinencia de la política pública con la Agenda de Desarrollo 2030. Sin embargo, si atendemos a las percepciones que algunos/as agricultores manifiestan según nuestro sondeo exploratorio, varios de esos programas no son reconocidos por las/os agricultores, como es el caso del BPA, lo que resulta consecuente con la información obtenida en la oficina del Senasa según la cual, a pesar de ser un importante programa nacional no se implementó en Río Gallegos. Por otro lado, otros programas si bien son conocidos, pocas personas de las sondeadas se identifican como partícipes de su cobertura (caso Sello PAF, MSA y Ley de Reparación Histórica). Podemos concluir, entonces, que la política del sector en su conjunto está sostenida principalmente por dos programas nacionales: ProHuerta y ReNAF.

Asimismo, el esfuerzo estatal con la promoción y el sostenimiento de la AF, que pudimos medir gracias a los indicadores de Capacidad estatal, tiene su origen en el nivel nacional. No identificamos ninguna política pública provincial definida en relación con la AF, y la política municipal se reduce, según nuestro sondeo, a la organización de Ferias productivas ocasionales.

Es importante señalar que valorar o calificar las políticas públicas a partir de estándares definidos y recomendados por un intérprete autorizado como el GTPSS, como hicimos en este trabajo de investigación, tiene la ventaja de permitir seguir con la observación en períodos futuros manteniendo criterios claros y reconocidos por los países, con una fuerte legitimidad social y política (Abramovich, 2006). Creemos que la utilización frecuente de esta estrategia permitirá estandarizar mecanismos útiles y homogéneos de evaluación y calificación que 
facilitarán la interpretación de los avances o retrocesos de las políticas públicas desde la perspectiva de los derechos humanos.

En este trabajo nos hemos centrado en la categoría Capacidad estatal, pero hay otras que pueden ser exploradas y medidas para completar el análisis. Algunos ejemplos son el Contexto financiero y el compromiso presupuestario, que apunta a ver cuánto se ha reflejado el compromiso estatal con el sostenimiento de la AF en las decisiones financieras del Estado; y también, el principio transversal de Igualdad y no discriminación, que es especialmente importante para visibilizar la dimensión del género. Una de las dimensiones en las que se producen y reproducen las desigualdades de género, y que debería ser tomada en cuenta especialmente en la planificación de las políticas públicas en general, es el acceso y el control de los recursos y beneficios por parte de las mujeres. La incorporación en el análisis de indicadores que permitan testear esta dimensión permitiría ver el nivel de atención por parte del Estado a una desigualdad social persistente: la brecha de género. Estas cuestiones dejan abierta la puerta para futuras investigaciones.

Finalmente, creemos importante mencionar que a partir del 2018 comienzan a verse los resultados del cambio en la orientación de la política nacional en relación a la AF, que impactan directamente en Río Gallegos, ya que, como vimos, los programas relevantes así como las instituciones de aplicación más reconocidas en el medio local, son de dependencia nacional: INTA en tanto gestionadora del ProHuerta, y SAF. La disminución de rango de las dependencias públicas nacionales, de Ministerios a Secretarías (ex Ministerio de Agricultura, Ganadería y Pesca), de Secretarías a Subsecretarías (la SAF que en 2017 fue absorbida por la Secretaría de Coordinación y Desarrollo Territorial y convertida en Subsecretaría de AF y Desarrollo Territorial), o la fusión de algunas de estas dependencias (como el actual Ministerio de Salud y Desarrollo Social), significa, la mayoría de las veces, cierre de oficinas regionales y/o achicamiento de personal y reducción presupuestaria, con lo cual menos técnicos/as trabajan con el sector. Por ello, aunque los programas no hayan desaparecido formalmente su implementación se ve limitada en la práctica, como pudimos ver en el caso de la SAF, cuyos integrantes se redujeron de 2 técnicos y 2 administrativos a 1 administrativo, con la consecuente reducción de las tareas en el terreno. Lo mismo sucedió con el ProHuerta que pasó de tener un equipo de alcance provincial, integrado por seis personas, con un coordinador propio, con fuerte presencia en Río Gallegos, a dos técnicos en esta localidad.

Desde 2018 también, observamos la transformación de algunos programas, como el MSA, que cambió las condiciones de cobertura, con lo cual muchas personas dejaron de estar incluidas en el programa. Aunque no se puede decir que a lo largo del país no hubo manifestaciones de resistencia a este cambio, creemos que la misma podría haber sido más fuerte si la autopercepción de la población como titular de derechos estuviera más instalada en las conciencias tanto individuales como colectivas. Resulta interesante, en este sentido, la percepción de abandono y necesidad de mayor presencia sostenida del Estado como testimonios de los mismos entrevistados/as, tal como se ha consignado en el trabajo.

Creemos que aquí puede estar la cuestión que permita garantizar la continuidad de las buenas políticas para la AF en particular, y para las políticas sociales en general. Incorporar la idea de que las/os ciudadanas/os son titulares de derechos cambia "la lógica de los procesos de elaboración de políticas... las acciones que se emprendan en este campo no son consideradas solamente como el cumplimiento de mandatos morales o políticos, sino como la vía escogida para dar cumplimiento a las obligaciones jurídicas, imperativas y exigibles, impuestas por los tratados de derechos humanos" (Abramovich, 2006, p.20). 


\section{REFERENCIAS}

ABRAMOVICH, V. (2006). Los Estándares Interamericanos de Derechos Humanos como Marco para la Formulación y el Control de las Políticas Sociales. Anuario de Derechos Humanos, (2), 13-51. https://doi.org/10.5354/0718-2279.2006.13370

ABRAMOVICH, V. y PAUTASSI, L. (2009). El enfoque de derechos y la institucionalidad de las políticas sociales. En V. Abramovich y L. Pautassi (Comp.), La revisión judicial de las políticas sociales. Estudio de casos. (pp. 279-340). Buenos Aires. Editores del Puerto. https://doi.org/10.18356/a48f3cca-es

BIRGI, J. (2018). La agricultura familiar en Santa Cruz y las frutas finas como alternativa productiva. (Tesis de Maestría). Facultad de Agronomía y Agroindustria. Universidad Nacional de Santiago del Estero. https://doi.org/10.19137/qs.v12i0.734

CIMADEVILLA, G y CARNIGLIA, E. (2008). La ruralización de la ciudad pampeana. En R. Thornton y G. Cimadevilla (Ed.), Grises de la Extensión, la Comunicación y el Desarrollo. (pp. 227-246). Buenos Aires. Ediciones INTA. https://doi.org/10.35537/10915/76394

FAO. (2018). Plataforma de conocimientos sobre agricultura familiar. Recuperado de http://www.fao.org/family-farming/detail/es/c/318261/

Indicadores de progreso para la medición de derechos contemplados en el Protocolo Adicional a la Convención Americana sobre Derechos Humanos en materia de derechos económicos, sociales y culturales "Protocolo de San Salvador". (2015). Preparado por Grupo de Trabajo para el Análisis de los Informes Anuales previstos por el Protocolo de San Salvador. OAS. Documentos oficiales, OEA/Ser.D/XXVI.11. https://doi.org/10.14201/gredos.137363

Ley $\mathrm{N}^{\circ} 27.118$ (2014). De Reparación Histórica de la Agricultura Familiar para la construcción de una nueva Ruralidad en la Argentina. En Boletín Oficial de la República Argentina. Buenos Aires. Argentina. https://doi.org/10.3989/ic.1980.v32.i319.2354

OLIVA, G. GONZÁLEZ, L. y RIAL, P. (2001) El ambiente en la Patagonia Austral. En P. Borelli y G. Oliva (Ed.), Ganadería Sustentable en la Patagonia Austral. (pp. 17-80). Ediciones INTA Región Patagonia https://doi.org/10.3989/aeamer.1998.v55.i2.351

PAUTASSI, L. (2010). Indicadores en materia de derechos económicos, sociales y culturales. Más allá de la medición. En V. Abramovich y L. Pautassi (Comp.), La medición de derechos en las políticas sociales. (pp. 1-87). Buenos Aires. Ediciones del Puerto. https://doi.org/10.35537/10915/71690

PÉREZ OROZCO, A. (2012). Prólogo. En V. Ezquivel (Ed.), La economía feminista desde América Latina: Una hoja de ruta sobre los debates actuales en la región. (pp. 13-23). Santo Domingo. ONU Mujeres. https://doi.org/10.1080/13545701.2017.1388533

VASSALLO, M. (2008). Los grises del desarrollo rural en el Uruguay a comienzos del siglo XXI. En R. Thornton y G. Cimadevilla (Ed.), Grises de la Extensión, la Comunicación y el Desarrollo. (pp. 283-308). Buenos Aires. Ediciones INTA. https://doi.org/10.35537/10915/55543 


\section{ANEXO 1 \\ ENCUESTA PRODUCTORES DE LA AF EN RÍO GALLEGOS}

Productorla $\mathrm{N}^{\circ}$

\section{Sexo}

Marca solo un óvalo.
Mujer
Varón
Otro:

2. ¿Cuál es la actividad productiva a la que se dedica?

Selecciona todos los que correspondan.

Producción Animal

Producción Agroindustrial - Agregado de valor

Producción Vegetal

3. ¿Recuerda desde cuándo se dedica a la actividad productiva?

4. ¿Conoce alguno de los siguientes Programas referidos a la AF? Selecciona todos los que correspondan.

\begin{tabular}{|c|c|c|c|c|c|c|}
\hline & $\begin{array}{c}\text { Registro } \\
\text { Nacional } \\
\text { de la } \\
\text { agricultura } \\
\text { familiar } \\
\text { (ReNaf) }\end{array}$ & ProHuerta & $\begin{array}{l}\text { Monotributo } \\
\text { Social } \\
\text { Agropecuario }\end{array}$ & $\begin{array}{c}\text { Sello } \\
\text { "Producido } \\
\text { por la AF" }\end{array}$ & $\begin{array}{l}\text { Programa } \\
\text { Nacional } \\
\text { Buenas } \\
\text { Prácticas } \\
\text { Agrícolas }\end{array}$ & $\begin{array}{c}\text { Ley } \\
\text { Nacional } \\
27.118 \text { de } \\
\text { Reparación } \\
\text { Histórica } \\
\text { de la AF }\end{array}$ \\
\hline \multicolumn{7}{|l|}{$\mathrm{SI}$} \\
\hline \multicolumn{7}{|l|}{ NO } \\
\hline $\mathrm{NS} / \mathrm{NC}$ & & & & & & \\
\hline
\end{tabular}

5. ¿Participó o fue incluida/o en alguno de los Programas mencionados? Selecciona todos los que correspondan.

\begin{tabular}{|c|c|c|c|c|c|c|}
\hline & $\begin{array}{c}\text { Registro } \\
\text { Nacional } \\
\text { de la } \\
\text { agricultura } \\
\text { familiar } \\
\text { (ReNaf) }\end{array}$ & ProHuerta & $\begin{array}{l}\text { Monotributo } \\
\text { Social } \\
\text { Agropecuario } \\
\text { (MSA) }\end{array}$ & $\begin{array}{c}\text { Sello } \\
\text { "Producido } \\
\text { por la AF" }\end{array}$ & $\begin{array}{c}\text { Programa } \\
\text { Nacional } \\
\text { de } \\
\text { Buenas } \\
\text { Prácticas } \\
\text { Agrícolas }\end{array}$ & $\begin{array}{c}\text { Ley } \\
\text { Nacional } \\
27.118 \text { de } \\
\text { Reparación } \\
\text { Histórica } \\
\text { de la AF }\end{array}$ \\
\hline \multicolumn{7}{|l|}{ SI } \\
\hline \multicolumn{7}{|l|}{ NO } \\
\hline $\mathrm{NS} / \mathrm{NC}$ & & & & & & \\
\hline
\end{tabular}


6. ¿Cuál de las siguientes instituciones colaboró/colabora, de alguna manera, con su actividad?

Selecciona todos los que correspondan.

\begin{tabular}{|c|c|c|c|c|c|c|}
\hline & INTA & SAF & $\begin{array}{l}\text { Consejo } \\
\text { Agrario } \\
\text { Provincial }\end{array}$ & $\begin{array}{l}\text { Ministerio de la } \\
\text { Producción, } \\
\text { comercio e } \\
\text { industria de la } \\
\text { Provincia de SC }\end{array}$ & $\begin{array}{c}\text { Secretaria de } \\
\text { desarrollo } \\
\text { comunitario de la } \\
\text { Municipalidad de } \\
\text { RG }\end{array}$ & SENASA \\
\hline \multicolumn{7}{|l|}{$\mathrm{SI}$} \\
\hline \multicolumn{7}{|l|}{ NO } \\
\hline $\mathrm{NS} / \mathrm{NC}$ & & & & & & \\
\hline
\end{tabular}

7. ¡Muchas gracias por sus respuestas! 


\section{ANEXO 2}

METAS ODS 2: Poner fin al hambre, lograr la seguridad alimentaria y la mejora de la nutrición y promover la agricultura sostenible.

\section{1}

Poner fin al hambre y asegurar el acceso de todas las personas, en particular los pobres y las personas en situaciones de vulnerabilidad, incluidos los niños menores de 1 año, a una alimentación sana, nutritiva y suficiente durante todo el año.

2.2

Poner fin a todas las formas de malnutrición, incluso logrando, a más tardar en 2025, las metas convenidas internacionalmente sobre el retraso del crecimiento y la emaciación de los niños menores de 5 años, y abordar las necesidades de nutrición de las adolescentes, las mujeres embarazadas y lactantes y las personas de edad

2.3

Duplicar la productividad agrícola y los ingresos de los productores de alimentos en pequeña escala, en particular las mujeres, los pueblos indígenas, los agricultores familiares, los ganaderos y los pescadores, entre otras cosas mediante un acceso seguro y equitativo a las tierras, a otros recursos e insumos de producción y a los conocimientos, los servicios financieros, los mercados y las oportunidades para añadir valor y obtener empleos no agrícolas

2.4

Asegurar la sostenibilidad de los sistemas de producción de alimentos y aplicar prácticas agrícolas resilientes que aumenten la productividad y la producción, contribuyan al mantenimiento de los ecosistemas, fortalezcan la capacidad de adaptación al cambio climático, los fenómenos meteorológicos extremos, las sequías, las inundaciones y otros desastres, y mejoren progresivamente la calidad de la tierra y el suelo

2.5

Mantener la diversidad genética de las semillas, las plantas cultivadas y los animales de granja y domesticados y sus correspondientes especies silvestres, entre otras cosas mediante una buena gestión y diversificación de los bancos de semillas y plantas a nivel nacional, regional e internacional, y promover el acceso a los beneficios que se deriven de la utilización de los recursos genéticos y los conocimientos tradicionales conexos y su distribución justa y equitativa, según lo convenido internacionalmente

\section{Elaborado con la información disponible en:}

2.a

Aumentar, incluso mediante una mayor cooperación internacional, las inversiones en infraestructura rural, investigación y servicios de extensión agrícola, desarrollo tecnológico y bancos de genes de plantas y ganado a fin de mejorar la capacidad de producción agropecuaria en los países en desarrollo, particularmente en los países menos adelantados

2.b

Corregir y prevenir las restricciones y distorsiones comerciales en los mercados agropecuarios mundiales, incluso mediante la eliminación paralela de todas las formas de subvención a las exportaciones agrícolas y todas las medidas de exportación con efectos equivalentes

\section{2.c}

Adoptar medidas para asegurar el buen funcionamiento de los mercados de productos básicos alimentarios y sus derivados y facilitar el acceso oportuno a la información sobre los mercados, incluso sobre las reservas de alimentos, a fin de ayudar a limitar la extrema volatilidad de los precios de los alimentos

\section{https://www.un.org/sustainabledevelopment/es/objetivos\%20de\%20desarrollo\%20sostenible/}

